\title{
Hypertension among Women with Diabetes Mellitus Patients of Single Ethnicity within 10 Years of Treatment
}

\author{
Ayalasomayajula Naga Sailaja ${ }^{1}$, Nivedita Nanda ${ }^{1, *}$, Bettadpura Shamanna Suryanarayana ${ }^{2}$, Gopal Krushna Pal ${ }^{3}$
}

\section{Ayalasomayajula Naga Sailaja ${ }^{1}$, Nivedita Nanda ${ }^{1, *}$, Bettadpura \\ Shamanna Suryanarayana², Gopal Krushna Pal ${ }^{3}$}

\section{'Department of Biochemistry, Jawaharla Institute of Postgraduate Medical Education and Research (JIPMER), Puducherry, INDIA. \\ ${ }^{2}$ Department of Medicine, Jawaharlal Institute of Postgraduate Medical Education and Research (JIPMER), Puducherry, INDIA. \\ ${ }^{3}$ Department of Physiology, Jawaharlal Institute of Postgraduate Medical Education and Research (JIPMER), Puducherry, INDIA. \\ *Correspondence}

\section{Dr. Nivedita Nanda}

Department of Biochemistry, JPMER, Puducherry-605 006, INDIA.

Phone: +91-9344628791

Email: drnnivedita@gmail.com

\section{History}

- Submission Date: 22-04-2021;

- Review completed: 17-05-2021;

- Accepted Date: 02-06-2021.

DOI : 10.5530/ijcep.2021.8.2.21

Article Available online

http://www.ijcep.org

\section{Copyright}

(c) 2021 Phcog.Net. This is an openaccess article distributed under the terms of the Creative Commons Attribution 4.0 International license.

\begin{abstract}
Background and Aim: Hypertension is often prevalent among diabetes patients. However the risk factors of hypertension are mostly affected by age, gender, and ethnicity, which are non-modifiable. Therefore, in the present study, we have analyzed the prevalence of hypertension and various risk factors associated with it among women with diabetes mellitus from Tamilian community. Methods: We conducted a cross-sectional survey of type 2 diabetes mellitus patients in our Institute hospital. We recruited female patients with Tamil origin of three generations. The case history and personal history and basal demographic parameters were noted down. Five $\mathrm{ml}$ of fasting blood was collected for routine analysis. Plasma was stored for estimation of osteoprotegerin (OPG) and insulin. Results: Hypertension was associated with family history of cardiovascular disease (CVD), abdominal obesity, dyslipidemia and higher rate pressure product. Conclusion: Diabetes women of Tamil community and with family history of CVD may benefit from weight loss, lifestyle modification and monitoring of blood pressure in early part of life.

Key words: Type 2 diabetes, CV risk, Endothelial dysfunction, RPP, Osteoprotegerin.
\end{abstract}

\section{INTRODUCTION}

Type 2 diabetes mellitus (T2D) is the leading cause of morbidity among all chronic non-communicable diseases in India. It is also a major health concern with socio-economic impact worldwide. ${ }^{[1,2]}$ Presence of $\mathrm{T} 2 \mathrm{D}$ raises the risk of cardiovascular $(\mathrm{CV})$ events by four-fold and the risk of cardiovascular death by two-fold. ${ }^{[3,4]}$ Hypertension is another leading non communicable disease in India. Its prevalent in in more than $50 \%$ of diabetes mellitus (DM) patients. vascular diseases in DM. ${ }^{[5]}$ Therefore, DM and hypertension both increase the risk for cardiovascular disease (CVD) by four-times in patients in comparison to healthy 2 controls. ${ }^{[6]}$ Though many T2D patients are not diagnosed with hypertension at the time of diagnosis, a cluster of them develop hypertension in few years despite being treated adequately for diabetes. There are studies in literature describing the prevalence of these two conditions at the onset. However, the data on prevalence of hypertension and associated risk factors in a diabetic population which is already under treatment has not been reported earlier.

CVD is the major macrovascular complication of both diabetes and hypertension. It has several modifiable non modifiable risk factors. Though these factors are influenced by several circulatory, inflammatory, vascular and neural components, atherosclerosis is the common point. In case of diabetes, more than atherosclerosis it is the vascular calcification which is Hypertension also contributes to micro- and macro- associated with diabetic cardiovascular disease. Osteoprotegerin is a biomarker of vascular calcification and associated with CVD. ${ }^{[7]}$ It is a decoy receptor for Receptor activator for NFkB Ligand (RANKL) and TNF related apoptosis inducing ligand (TRAIL). However, OPG level in diabetic population with and without hypertension has not been reported so far.

Age, gender, and ethnicity are few traditional nonmodifiable risk factors associated with CVD. Though population, the risk of CVD starts setting in after the age of forty. Similarly, though after menopause though risk is equal in terms of gender, the male gender per se adds to higher risk of CVD. Therefore, in the present study we have analysed the prevalence of diabetes and hypertension along with their risk profile among female T2D patients belonging to south Indian Tamil community who has been taking standard treatment for less than 10 years in the hospital our Institute.

This is a hospital-based cross-sectional study conducted in Jawaharlal Institute of Postgraduate Medical Education and Research (JIPMER), Puducherry, a tertiary care hospital, we collected data from the T2D patients under treatment visiting diabetic OPD from 2019 to 2020. After approval from Institute both diseases are quite common even in younger

\section{MATERIALS AND METHODS}

\section{Study Setting}

Cite this article: Sailaja AN, Nanda N, Suryanarayana BS, Pal GK. Hypertension among Women with Diabetes Mellitus Patients of Single Ethnicity within 10 Years of Treatment. Int J Clin Exp Physiol. 2021;8(2):95-9. 
Review Board (JSAC) and Institutional Ethics Committee, all patients under standard oral antidiabetic treatment for more than two years but less than 10 years were screened. Written informed consent was obtained from all participants at the time of recruitment.

\section{Inclusion Criteria}

Female T2D patients receiving metformin and glimepiride combination, within the age range of 40 to 60 years, were contacted for the study. Patients with Tamil origin traced to three generations from both parents' sides were included in the study.

\section{Exclusion Criteria}

Patients with Type 1 diabetes mellitus, insulin/ or glucocorticoid therapy, BMI exceeding $35 \mathrm{~kg} / \mathrm{m}^{2}$ and with history of CVD were excluded from the study.

\section{Study Procedure}

Patients were explained about the purpose of the study. Those who volunteered to participate were taken to the biochemistry and physiology labs. They were made to rest on a chair for $5 \mathrm{~min}$ and their basal heart rate, systolic and diastolic blood pressure was recorded using an automatic BP monitor apparatus (Omron Healthcare Co. Ltd, Kyoto, Japan). For each patient, blood pressure was recorded twice in each arm with $5 \mathrm{~min}$ interval. The mean values were used for analysis. The fasting blood samples were collected for analysis of glucose and lipid profile as part of their routine investigation using commercial kits for biochemistry autoanalyzer. Glycated hemoglobin was estimated by commercial kits using turbidimetry. $2 \mathrm{ml}$ of plasma was stored at $-40^{\circ} \mathrm{C}$ deep fridge for further analysis of osteoprotegerin (OPG) by Elisa.

They were interviewed about their personal details, case history and family history. Data was collected using a semi structured close ended proforma. Height and weight were recorded in Physiology lab and body mass index (BMI) was calculated. BMI was categorized as less than $22.9 \mathrm{Kg} / \mathrm{m}^{2}$ (normal weight) and $\geq 23 \mathrm{Kg} / \mathrm{m}^{2}$ (overweight and obese). Physical activity was categorized as sedentary (most of the time sitting, standing, driving etc) and active (most of the time walking, lifting, cleaning etc for most of the time of the day). Hypertension was noted down based on drugs taken from their case records. Triglyceride was categorized as normal $(\leq 150 \mathrm{mg} / \mathrm{dL})$ and dyslipidemia $(>150 \mathrm{mg} / \mathrm{dL})$. HDL cholesterol was categorized as normal $(\geq 40 \mathrm{mg} / \mathrm{dL})$ and dyslipidemia $(<40 \mathrm{mg} / \mathrm{dL})$. Dyslipidemia was defined as per NCEP guidelines. ${ }^{[8]}$ Based on HbAlc level, glycemic status was categorized as good control $(<7 \mathrm{~g} \%$ of $\mathrm{Hb})$, adequate control (7-8 $\mathrm{g} \%$ of $\mathrm{Hb})$, Inadequate control $(8-9 \mathrm{~g} \%$ of $\mathrm{Hb})$ and uncontrolled ( $>9 \mathrm{~g} \%$ of $\mathrm{Hb})$.

\section{Statistical Analysis of Data}

The Clinical variables were expressed as percentages for categorical variables. Continuous variables were expressed as Mean \pm SD. The normality distribution of data was checked by the Shapiro-Wilk test. For comparison between two groups, for Chi square test, Student's unpaired $t$ test and Mann-Whitney $U$ test were used for nominal data, continuous parameters, and non- normally distributed parameters, respectively. All statistical tests were performed using SPSS version 20.0. P Value $<0.05$ was considered significant.

\section{RESULTS}

The sociodemographic characteristics of the T2D patients are shown in Table 1. There were a greater number of patients in the age range of 45-64 years (close to $85 \%$ ) and with BMI higher than $23 \mathrm{Kg} / \mathrm{m}^{2}$. Majority of them were from Hindu community and were homemakers with a
Table 1: Socio-demographic characteristics of Tamil women with diabetes mellitus (DM) patients on standard treatment for less than 10 years).

\begin{tabular}{|c|c|c|}
\hline Characteristics & Number $(n=61)$ & Percentage (\%) \\
\hline Age (Years) $($ Mean \pm SD) & $51.86 \pm 5.89$ & \\
\hline$\leq 44$ & 9 & $14.75 \%$ \\
\hline $45-64$ & 52 & $85.24 \%$ \\
\hline \multicolumn{3}{|l|}{ Diseases Duration (Years) } \\
\hline$\leq 5$ & 35 & $57.4 \%$ \\
\hline $5-10$ & 26 & $42.6 \%$ \\
\hline \multicolumn{3}{|l|}{ Body mass Index } \\
\hline$\leq 22.9 \mathrm{Kg} / \mathrm{m}^{2}$ & 32 & $52.45 \%$ \\
\hline$>25 \mathrm{Kg} / \mathrm{m}^{2}$ & 29 & $47.54 \%$ \\
\hline \multicolumn{3}{|l|}{ Family History HTN } \\
\hline No & 30 & $49.2 \%$ \\
\hline Yes & 31 & $50.8 \%$ \\
\hline \multicolumn{3}{|l|}{ Family History DM } \\
\hline No & 26 & $42.6 \%$ \\
\hline Yes & 35 & $57.4 \%$ \\
\hline \multicolumn{3}{|l|}{ Family History CVD } \\
\hline No & 46 & $75.4 \%$ \\
\hline Yes & 15 & $24.6 \%$ \\
\hline \multicolumn{3}{|l|}{ Religion } \\
\hline Hindu & 57 & $93.4 \%$ \\
\hline Christian & 4 & $6.6 \%$ \\
\hline Others & 0 & 0 \\
\hline \multicolumn{3}{|l|}{ Occupation } \\
\hline Home maker & 40 & $65.6 \%$ \\
\hline Working women & 21 & $34.4 \%$ \\
\hline \multicolumn{3}{|l|}{ Physical activity } \\
\hline Sedentary & 40 & $65.6 \%$ \\
\hline Active & 21 & $34.4 \%$ \\
\hline \multicolumn{3}{|l|}{ Lipid Profile } \\
\hline Normal TG & 32 & $52.5 \%$ \\
\hline Dyslipidemia TG & 29 & $47.5 \%$ \\
\hline Normal HDL & 13 & $21.3 \%$ \\
\hline Dyslipidemia HDL & 48 & $78.7 \%$ \\
\hline \multicolumn{3}{|l|}{ Glycemic status (g\% of $\mathrm{Hb}$ ) } \\
\hline$<7$ (good control) & 26 & $42.6 \%$ \\
\hline 7-8 (adequate control) & 15 & $24.6 \%$ \\
\hline 8-9 (inadequate control) & 8 & $13.1 \%$ \\
\hline$>9$ (uncontrolled) & 12 & $19.7 \%$ \\
\hline
\end{tabular}

HTN: Hypertension; DM: Diabetes mellitus; CVD: Cardiovascular disease; TG: Triglyceride; HDL: High density lipoprotein

sedentary lifestyle. None of them presented with a history of alcohol consumption.

The risk profile associated with hypertension is shown in Table 2. They were equally distributed in all quartiles in terms of age, disease duration and BMI. There was no significant difference in the distribution of family history of diabetes and hypertension. However, family history of CVD 
Table 2: Factors associated with hypertension among Tamil women with diabetes mellitus (DM) patients on treatment.

\begin{tabular}{|c|c|c|c|c|}
\hline \multirow[t]{2}{*}{ Factor } & \multicolumn{2}{|c|}{ Hypertension } & \multirow[t]{2}{*}{$\chi^{2}$} & \multirow[t]{2}{*}{$\mathbf{P}$} \\
\hline & $(n=32)$ & $(n=29)$ & & \\
\hline & No & Yes & & \\
\hline \multicolumn{5}{|l|}{ Age (years) } \\
\hline$<44$ & $5(15.6 \%)$ & $4(13.8 \%)$ & 0.41 & 0.84 \\
\hline $45-64$ & $27(84.4 \%)$ & $25(86.2 \%)$ & & \\
\hline \multicolumn{5}{|l|}{$\begin{array}{c}\text { Diseases Duration } \\
\text { (years) }\end{array}$} \\
\hline$\leq 5$ & $19(59.4 \%)$ & $16(55.2 \%)$ & 0.110 & 0.740 \\
\hline $5-10$ & $13(40.6 \%)$ & $13(44.8 \%)$ & & \\
\hline \multicolumn{5}{|l|}{ Body mass Index } \\
\hline$\leq 22.9 \mathrm{Kg} / \mathrm{m}^{2}$ & $3(9.4 \%)$ & $1(3.4 \%)$ & & \\
\hline$\geq 23 \mathrm{Kg} / \mathrm{m}^{2}$ & $29(90.6 \%)$ & $28(96.6 \%)$ & 0.87 & 0.35 \\
\hline \multicolumn{5}{|l|}{$\begin{array}{c}\text { Family History } \\
\text { HTN }\end{array}$} \\
\hline No & $16(50 \%)$ & $14(48.3 \%)$ & & \\
\hline Yes & $16(50 \%)$ & $15(51.7 \%)$ & 0.018 & 0.890 \\
\hline \multicolumn{5}{|l|}{$\begin{array}{c}\text { Family History } \\
\text { DM }\end{array}$} \\
\hline No & $17(53.1 \%)$ & $9(31.0 \%)$ & & \\
\hline Yes & $15(46.9 \%)$ & $20(69.0 \%)$ & 3.03 & 0.081 \\
\hline \multicolumn{5}{|l|}{$\begin{array}{l}\text { Family History } \\
\text { CVD }\end{array}$} \\
\hline No & $28(87.5 \%)$ & $18(62.1 \%)$ & & \\
\hline Yes & $4(12.5 \%)$ & $11(37.9 \%)$ & 5.3 & 0.021 \\
\hline \multicolumn{5}{|l|}{ Occupation } \\
\hline Homemaker & $23(71.9 \%)$ & $22(75.9 \%)$ & 0.01 & 0.990 \\
\hline Working & $9(28.1 \%)$ & $7(24.1 \%)$ & & \\
\hline \multicolumn{5}{|l|}{ Religion } \\
\hline Hindu & $30(93.8 \%)$ & $27(93.1 \%)$ & 0.01 & 0.990 \\
\hline Christian & $2(6.2 \%)$ & $2(6.9 \%)$ & & \\
\hline Others & 0 & 0 & & \\
\hline \multicolumn{5}{|l|}{ Physical activity } \\
\hline Active & $10(31.2 \%)$ & $11(37.9 \%)$ & 0.301 & 0.583 \\
\hline Sedentary & $22(68.8 \%)$ & $18(62.1 \%)$ & & \\
\hline \multicolumn{5}{|l|}{ Lipid Profile } \\
\hline Normal TG & $18(56.2 \%)$ & $14(48.3 \%)$ & & \\
\hline Dyslipidemia TG & $14(43.8 \%)$ & $15(51.7 \%)$ & 0.33 & 0.53 \\
\hline Normal HDL & $10(31.2 \%)$ & $3(10.0 \%)$ & 3.96 & 0.046 \\
\hline Dyslipidemia HDL & $22(68.8 \%)$ & $26(90.0 \%)$ & & \\
\hline \multicolumn{5}{|l|}{$\begin{array}{c}\text { Glycemic status } \\
\text { (g\% of } \mathrm{Hb})\end{array}$} \\
\hline$<7$ (good control) & & $14(43.8 \%)$ & $12(40.0 \%)$ & \\
\hline $7-8$ & $7(21.9 \%)$ & $8(26.7 \%)$ & & \\
\hline $8-9$ & $7(21.9 \%)$ & $1(3.3 \%)$ & 6.58 & 0.086 \\
\hline$>9$ & $4(12.5 \%)$ & $9(30 \%)$ & & \\
\hline
\end{tabular}

HTN: Hypertension; DM: Diabetes mellitus; CVD: Cardiovascular disease; TG: Triglyceride; HDL: High density lipoprotein was significantly higher in T2D patients with hypertension $(\mathrm{P}<0.021)$. in this group, more than $78 \%$ had dyslipidemia in terms of low HDL cholesterol $(\mathrm{P}<0.046)$. In the upper quartile, around $19 \%$ did not have optimum glycemic control $(\mathrm{P}<0.086)$ among the $\mathrm{T} 2 \mathrm{D}$ patients with hypertension.

The comparison of biochemical and physiological parameters is shown in Table 3. Waist hip ratio, SBP, DBP, MAP and RPP were significantly

Table 3: Characteristics of the study population, clinical and laboratory findings of Tamil women with diabetes mellitus (DM) patients on treatment) with and without hypertension (HTN).

\begin{tabular}{|c|c|c|c|}
\hline Variables & $\begin{array}{c}\text { Control Group } \\
\text { (DM without HTN) } \\
(n=32)\end{array}$ & $\begin{array}{c}\text { Test Group } \\
\text { (DM with HTN) } \\
(n=29)\end{array}$ & $P$ values \\
\hline \multicolumn{4}{|l|}{$\begin{array}{l}\text { Socio demographic } \\
\text { parameters }\end{array}$} \\
\hline Age (Years) & $52.00 \pm 6.50$ & $51.75 \pm 5.77$ & 0.879 \\
\hline Smoking: $\mathrm{n}(\%) \psi$ & $1(1.6 \%)$ & $0(0 \%)$ & 0.253 \\
\hline \multicolumn{4}{|l|}{$\begin{array}{l}\text { Anthropometric } \\
\text { parameters }\end{array}$} \\
\hline $\mathrm{BMI}\left(\mathrm{Kg} / \mathrm{m}^{2}\right)$ & 25. $56 \pm 3.98$ & $26.53 \pm 3.65$ & 0.076 \\
\hline $\mathrm{WHR}^{*}$ & $0.95 \pm 0.05$ & $0.93 \pm 0.04$ & 0.010 \\
\hline \multicolumn{4}{|l|}{$\begin{array}{l}\text { BHR and BP } \\
\text { parameters }\end{array}$} \\
\hline BHR (beats per min) & $75.21 \pm 9.99$ & $78.10 \pm 9.54$ & 0.255 \\
\hline $\mathrm{SBP}(\mathrm{mmHg})^{*}$ & $118.53 \pm 9.98$ & $131.62 \pm 13.87$ & 0.000 \\
\hline $\mathrm{DBP}(\mathrm{mmHg}) *$ & $76.71 \pm 7.07$ & $81.41 \pm 9.42$ & 0.031 \\
\hline $\operatorname{MAP}(\mathrm{mmHg}) *$ & $90.65 \pm 6.98$ & $97.86 \pm 11.16$ & 0.003 \\
\hline $\mathrm{RPP}(\mathrm{mmHg} / \mathrm{min}) *$ & $89.21 \pm 14.53$ & $102.61 \pm 1551$ & 0.001 \\
\hline \multicolumn{4}{|l|}{$\begin{array}{l}\text { Glycaemic } \\
\text { Parameters }\end{array}$} \\
\hline Glucose (mg/dL) & $129.62 \pm 35.57$ & $127.25 \pm 28.39$ & 0.776 \\
\hline $\mathrm{HbA}_{1 \mathrm{c}}(\mathrm{g} \%)$ & $7.80 \pm 1.33$ & $8.17 \pm 1.79$ & 0.370 \\
\hline Insulin $(\mu \mathrm{U} / \mathrm{mL})$ & $20.82 \pm 15.46$ & $27.42 \pm 17.81$ & 0.127 \\
\hline HOMA-IR & $6.59 \pm 5.29$ & $8.36 \pm 4.92$ & 0.067 \\
\hline IDRS & $58.57 \pm 11.67$ & $63.33 \pm 11.54$ & 0.308 \\
\hline \multicolumn{4}{|l|}{ Lipid profile } \\
\hline $\mathrm{TC}(\mathrm{mg} / \mathrm{dL})$ & $155.62 \pm 36.43$ & $160.83 \pm 41.66$ & 0.605 \\
\hline HDL C (mg /dL) & $37.37 \pm 5.71$ & $35.31 \pm 4.89$ & 0.137 \\
\hline LDL C (mg /dL) & $87.83 \pm 31.03$ & $95.06 \pm 35.27$ & 0.398 \\
\hline $\mathrm{TG}(\mathrm{mg} / \mathrm{dL})$ & $152.09 \pm 66.44$ & $152.28 \pm 58.46$ & 0.991 \\
\hline VLDL C (mg /dL) & $30.41 \pm 13.28$ & $30.45 \pm 11.69$ & 0.991 \\
\hline \multicolumn{4}{|l|}{$\begin{array}{l}\text { Other biochemical } \\
\text { markers }\end{array}$} \\
\hline $\begin{array}{l}\text { Osteoprotegerin (pg/ } \\
\mathrm{mL}) \#\end{array}$ & $230.44 \pm 97.45$ & $291.05 \pm 140.79$ & 0.098 \\
\hline
\end{tabular}

The values are expressed as Mean $\pm \mathrm{SD}$ for parametric data. Comparison between the groups was done by Chi square test for categorical variables $(\psi)$; unpaired Student's $t$ test for parametric data $\left({ }^{*}\right)$ and by Mann-Whitney $\mathrm{U}$ test for non-parametric data (\#). $\mathrm{P}$ Value $<0.05$ was considered significant. HTN: Hypertension; DM: Diabetes mellitus; CVD: Cardiovascular disease; HOMA-IR: homeostatic model assessment of insulin resistance; TC: Total cholesterol; TG: Triglyceride; HDL: High density lipoprotein; LDL: Low density lipoprotein; VLDL: Very low-density lipoprotein; OPG: Osteoprotegerin. 
higher in T2D patients with hypertension compared to T2D patients without hypertension. The difference between HOMA-IR, IDRS and HbA1c was not statistically significant. Plasma OPG was higher but it was not statistically significant in hypertensive T2D patients.

\section{DISCUSSION}

India is projected to be the diabetic capital of the world due to the rising population of diabetes patients. Though diabetes itself is a major risk factor of CVD, the combination of insulin resistance and hypertension worsens this CVD risk profile and needs appropriate intervention. The present study is unique in its findings as the study population is ethnically segregated from all other diabetes patients attending JIPMER OPD from various corners of southern India. Therefore, the risk profile reported in our study is exclusive to the South Indian Tamil community female patients.

Our report shows that majority of female T2D patients were overweight or obese leading a sedentary lifestyle. However, unlike other reports sedentary lifestyle was not a contributing factor of hypertension (Table 2). Among them those who also developed hypertension had a significantly higher frequency of family history of CVD. The family history of diabetes and hypertension was not individually statistically significant. It is well known that DM and hypertension are two major risk factors for CVD. Therefore, our finding suggests that women with a family history of CVD should adopt diet and lifestyle modification early in their life, even if they are non-diabetic and non-hypertensive when compared to those with family history of diabetes or hypertension alone. We grouped the age of the participants based on the international guidelines of age ${ }^{[9]}$ Majority of the patients $(85 \%)$ were in the aging adult stage and very few were in the middle adult stage (Table 1). However, increased age did not have a significant association with prevalence of hypertension (Table 2). Therefore, this can be interpreted that, the early intervention might benefit the first-degree relatives of CVD patients in delaying the onset of both hypertension and diabetes, and not hypertension among diabetes.

The distribution frequency of various religion and occupation was similar in both groups (diabetes with and without hypertension) which is shown in Table 2. None of the participants had history of alcohol consumption. Except one participant none of them were smokers (Table 3). Therefore, in our study population effects of these risk factors were absent. Duration of the disease was the other finding in our report, which was also equally distributed in this study (Table 2). This suggests that risk factors contributing to development of hypertension might not be influenced by the time effect. Though in present population there was no significant association of physical inactivity and BMI with hypertension, T2D women with hypertension had significantly higher degree of abdominal obesity which was reflected in terms of waist hip ratio $(\mathrm{P}<0.010$; Table 3). Hypertension and obesity influence each other bidirectionally. Moreover, hypertension is strongly associated with central obesity when compared to generalized obesity. Therefore, our findings corroborate with the previous reports. ${ }^{[10]}$ Few mechanisms through which obesity may cause hypertension could be the activation of sympathetic nervous system or via activation of renin- angiotensin system. When we compared the glycemic, lipid profile and blood pressure parameters between T2D patients with and without hypertension (Table 3 ), there was no significant difference in the mean glycemic and lipid profile. All parameters of blood pressure were higher in hypertensive diabetes, and they had a higher rate pressure product (RPP). RPP is a measure of myocardial oxygen consumption. It depends on basal heart rate and systolic blood pressure. The higher RPP in hypertensive diabetes women indicates increased cardiac workload even at rest. RPP is a known CV risk factor. ${ }^{[11]}$ Therefore, hypertensive women with T2D are at increased risk of CVD in our study.
Though lipid profile was similar in both the groups (Table 3), when we compared these profile values at different levels (normal level versus dyslipidaemia), hypertension was associated with dyslipidemia in terms of higher TG and low HDL (Table 2). Previous report suggests that despite treatment variables of metabolic syndromes persist in diabetes patients. ${ }^{[12]}$ High triglyceride is one such variable of metabolic syndrome. Therefore, this report supports our finding. However, Yadav et al. had assessed the diabetes patients of both genders and of all ethnicities. The novelty of our report is that we have recruited pertains of single gender and ethnicity, which is a report of its first kind.

High triglyceride adds to triglyceride rich lipoprotein (TLR) load in circulation which consists of chylomicron and very low density cholesterol. TLR is more atherogenic than LDL as it does not need any oxidation or modification to exert its atherogenicity. ${ }^{[13]}$ Therefore, the association of dyslipidemia in terms of high TG and low HDL in hypertensive T2D women is indicative of high degree of atherosclerosis in these patients. There are other biochemical markers of atherosclerosis. Osteoprotegerin is one such marker which at high level in circulation indicates higher degree of atherosclerosis.

In our previous reports, we had described higher osteoprotegerin level in diabetes compared to healthy control despite standard treatment. ${ }^{[14]}$ In this study, we report a similar pattern of higher OPG, T2D women with hypertension though it did not reach statistical significance between two disease groups, which might be due to a sample size. Our finding suggests that there might be a higher degree of vascular calcification in T2D patients when associated with hypertension. OPG is secreted from various cells in the body. One such source is adipocyte. ${ }^{[15]}$ As hypertensive diabetes women had higher central obesity, this could be a contributing factor for the rising trend of OPG. However, further studies are required to confirm whether there are other mechanisms apart from adiposity which might lead to increase OPG level in these patients.

\section{Limitations of the study}

We have not completed the data analysis of heart rate variability, an excellent marker of cardiovascular risk, in the present study which is a limitation of this report.

\section{CONCLUSION}

Women with type 2 diabetes mellitus with a family history of cardiovascular disease are more likely to develop hypertension which adds to their cardiovascular risk profile within 10 years, despite taking antidiabetic treatment. Maintaining a healthy lipid profile and ideal body weight especially waist-hip ratio is more important for these patients. We suggest periodic evaluation of markers of atherosclerosis and vascular calcification in diabetic women. The inclusion of newer markers such as OPG/RANKL ratio might be considered for evaluation of chronic diabetes patients.

Future studies should be performed to explore the benefits of lifestyle modification and weight loss early in the life of first-degree relatives of CVD compared to those with family history of diabetes or hypertension alone.

\section{ACKNOWLEDGEMENTS}

The authors acknowledge the financial assistance from JIPMER Authority to the first author as part of her $\mathrm{PhD}$ thesis work.

\section{CONFLICT OF INTEREST}

The authors declare no conflict of interest. 


\section{ABBREVIATIONS}

OPG: Osteoprotegerin; CVD: Cardiovascular Disease; DM: Diabetes Mellitus; TRAIL: TNF Related Apoptosis Inducing Ligand; RPP: Rate Pressure Product; TLR: Triglyceride Rich Lipoprotein.

\section{REFERENCES}

1. Wild S, Roglic G, Green A, Sicree R, King H. Global prevalence of diabetes: estimates for the year 2000 and projections for 2030. Diab Care. 2004;27(5):1047-53. doi: 10.2337/diacare.27.5.1047, PMID 15111519.

2. Mudaliar S. New frontiers in the management of type 2 diabetes. Indian J Med Res. 2007;125(3):275-96. PMID 17496356.

3. Tzoulaki I, Molokhia M, Curcin V, Little MP, Millett CJ, Ng A, Hughes RI, Khunti K, Wilkins MR, Majeed A, Elliott P. Risk of cardiovascular disease and all cause mortality among patients with type 2 diabetes prescribed oral antidiabetes drugs: retrospective cohort study using UK general practice research database. BMJ. 2009;339:b4731. doi: 10.1136/bmj.b4731, PMID 19959591.

4. Turner RC, Millns H, Neil HA, Stratton IM, Manley SE, Matthews DR, Holman RR. Risk factors for coronary artery disease in non-insulin dependent diabetes mellitus: United Kingdom Prospective Diabetes Study (UKPDS: 23). BMJ. 1998;316(7134):823-8. doi: 10.1136/bmj.316.7134.823, PMID 9549452.

5. Lastra G, Syed S, Kurukulasuriya LR, Manrique C, Sowers JR. Type 2 diabetes mellitus and hypertension: an update. Endocrinol Metab Clin North Am. 2014;43(1):103-22. doi: 10.1016/j.ecl.2013.09.005, PMID 24582094.

6. Hu G, Jousilahti P, Tuomilehto J. Joint effects of history of hypertension at baseline and type 2 diabetes at baseline and during follow-up on the risk of coronary heart disease. Eur Heart J. 2007:28(24):3059-66. doi: 10.1093/eurheartj/ehm501, PMID 17981826.

7. Tschiderer L, Willeit J, Schett G, Kiechl S, Willeit P. Osteoprotegerin concen- tration and risk of cardiovascular outcomes in nine general population studies: literature-based meta-analysis involving 26,442 participants. PLOS ONE. 2017;12(8):e0183910. doi: 10.1371/journal.pone.0183910, PMID 28837646.

8. Lee Y, Siddiqui WJ. Cholesterol levels. StatPearls [Internet]. 2020 Jul 26:2021 Jan-. PMID: 31194434.

9. Rowbottom R, In SN. The stages of life - A new look. Rowbottom and Spicer Co. Ltd. Internet Publications; 2010. p. 7-14

10. Wohlfahrt P, Somers VK, Cifkova R, Filipovsky J, Seidlerova J, Krajcoviechova A, Sochor O, Kullo IJ, Lopez-Jimenez F. Relationship between measures of central and general adiposity with aortic stiffness in the general population. Atherosclerosis. 2014;235(2):625-31. doi: 10.1016/j.atherosclerosis.2014.05.958, PMID 24968316.

11. White WB. Heart rate and the rate-pressure product as determinants of cardiovascular risk in patients with hypertension. Am J Hypertens. 1999;12(2 Pt 2):50S-5S. doi: 10.1016/s0895-7061(98)00280-5, PMID 10090295.

12. Yadav D, Mishra M, Tiwari A, Bisen PS, Goswamy HM, Prasad GBKS. Prevalence of dyslipidemia and hypertension in Indian type 2 diabetic patients with metabolic syndrome and its clinical significance. Osong Public Health Res Perspect. 2014;5(3):169-75. doi: 10.1016/j.phrp.2014.04.009.

13. Nordestgaard BG, Varbo A. Triglycerides and cardiovascular disease. Lancet. 2014;384(9943):626-35. doi: 10.1016/S0140-6736(14)61177-6.

14. Jasmine MR, Nanda N, Sahoo J, Velkumary S, Pal GK. Increased osteoprotegerin level is associated with impaired cardiovagal modulation in type-2 diabetic patients treated with oral antidiabetic drugs. BMC Cardiovasc Disord. 2020;20(1):453. doi: 10.1186/s12872-020-01729-1, PMID 33081726.

15. An JJ, Han DH, Kim DM, Kim SH, Rhee Y, Lee EJ, Lim SK. Expression and regulation of osteoprotegerin in adipose tissue. Yonsei Med J. 2007;48(5):765-72. doi: 10.3349/ymj.2007.48.5.765, PMID 17963332.

Cite this article: Sailaja AN, Nanda N, Suryanarayana BS, Pal GK. Hypertension among Women with Diabetes Mellitus Patients of Single Ethnicity within 10 Years of Treatment. Int J Clin Exp Physiol. 2021;8(2):95-9. 